Pacific Journal of Mathematics

REPRESENTATION OF REAL NUMBERS BY GENERALIZED 


\title{
REPRESENTATION OF REAL NUMBERS BY GENERALIZED GEOMETRIC SERIES
}

\author{
E. A. MAIER
}

We shall say that the series of real numbers, $\sum_{i=0}^{\infty} 1 / a_{i}$, is a generalized geometric series (g.g.s.) if and only if $a_{i}^{2} \leqq a_{i+1} a_{i-1}$ for all $i \geqq 1$. (Note that the series is geometric if and only if equality holds.) In this paper we investigate the representation of positive real numbers less than or equal to one by generalized geometric series of the form $\sum_{i=0}^{\infty} x^{i} / c_{\imath}$ where the $c_{i}$ are positive integers and $x \geqq 1$.

1. Preliminary results.

LEMMA 1. If $\sum_{i=0}^{\infty} 1 / a_{i}$ is a g.g.s. and

$$
\left|a_{k}\right|<\left|a_{k+1}\right|, \text { then } \sum_{i=k+1}^{\infty}\left|\frac{1}{a_{i}}\right| \leqq \frac{1}{\left|a_{k+1}\right|-\left|a_{k}\right|}
$$

Proof. Since $\left|a_{k} / a_{k+t}\right| \leqq\left|a_{k} / a_{k+1}\right|^{t}$ for all $t \geqq 1$, we have

$$
\sum_{i=k+1}^{\infty} \frac{1}{\left|a_{i}\right|} \leqq \frac{1}{\left|a_{k}\right|} \sum_{i=1}^{\infty}\left|\frac{a_{k}}{a_{k+1}}\right|^{t}=\frac{1}{\left|a_{k+1}\right|-\left|a_{k}\right|}
$$

The following theorem readily follows from Lemma 1.

THEOREM 1. The g.g.s. $\sum_{i=0}^{\infty} 1 / a_{i}$ converges if and only if there exists $k$ such that $\left|a_{k}\right|<\left|a_{k+1}\right|$.

THEOREM 2. Let $\sum_{i=0}^{\infty} 1 / a_{i}$ be a g.g.s. with $0<a_{0}<a_{1}$. Let $\alpha=$ $\sum_{i=1}^{\infty} 1 / a_{i}, S_{k}=\sum_{i=0}^{k} 1 / a_{i}$ and $t_{k+1}=a_{k+1} / a_{k}-1$. Then

(i) the sequence of half-open intervals $\left\{\left(S_{k}, S_{k}+1 /\left(a_{k+1}-a_{k}\right)\right]\right\}$ is a sequence of nested intervals whose intersection is $\alpha$,

(ii) $t_{k} \leqq t_{k+1} \leqq 1 / a_{k}\left(\alpha-S_{k}\right)$.

Proof. Since the series is a g.g.s., we have

$$
\frac{1}{a_{k+1}-a_{k}} \geqq \frac{1}{a_{k+1}}+\frac{1}{a_{k+2}-a_{k+1}} \text {. }
$$

Hence the sequence of intervals in (i) above is nested. Also $a_{k}<a_{k+1}$ for all $k \geqq 0$. Thus, using Lemma 1 ,

$$
S_{k}<\alpha \leqq S_{k}+\frac{1}{a_{k+1}-a_{k}}=S_{k}+\frac{1}{a_{k} t_{k+1}}
$$


Since $a_{k} / a_{k+1} \leqq a_{0} / a_{1}$ for all $k \geqq 0$, we have

$$
0 \leqq \lim _{k \rightarrow \infty} \frac{1}{a_{k+1}-a_{k}} \leqq \lim _{k \rightarrow \infty} \frac{1}{a_{k}\left(\frac{a_{1}}{a_{0}}-1\right)}=0 \text {, }
$$

and it follows from (1) that the intervals converge to $\alpha$.

Inequalities (ii) are obtained from (1) and the definition of $t_{k}$.

Corollary. Let $x>0$ and let $\alpha=\sum_{i=0}^{\infty} x_{i} / c_{i}$ be $a$ g.g.s. with $0<c_{0} x<c_{1}$; let $S_{k}=\sum_{i=0}^{k} x^{i} / c_{i}$ and $s_{k+1}=c_{k+1} / c_{k}-1$. Then

(i) the sequence of half-open intervals $\left\{\left(S_{k}, S_{k}+x^{k+1} /\left(c_{k+1}-x c_{k}\right)\right]\right\}$ is a sequence of nested intervals whose intersection is $\alpha$,

(ii) $s_{k} \leqq s_{k+1} \leqq x^{k+1} /\left(c_{k}\left(\alpha-S_{k}\right)\right)+(x-1)$.

Proof. Apply the theorem with $a_{k}=c_{k} / x^{k}$ observing that in this case

$$
t_{k+1}=\frac{c_{k+1}}{x c_{k}}-1=\frac{s_{k+1}+1}{x}-1 .
$$

3. The representation of reals. The corollary to Theorem 2 suggests an algorithm for constructing a g.g.s. of the form $\sum_{i=0}^{\infty} x^{i} / c_{i}$, where the $c_{i}$ are integers and $x \geqq 1$, which converges to a given positive real number $\beta \leqq 1$.

To obtain such a series let $\left\{s_{0}, s_{1}, s_{2} \cdots\right\}$ be any sequence of positive integers such that $s_{0}=[1 / \beta]$ and, for $k \geqq 0$,

$$
\max \left\{\frac{x^{k+1}}{c_{k}\left(\beta-S_{k}\right)}-1, s_{k}-1\right\}<s_{k+1} \leqq \frac{x^{k+1}}{c_{k}\left(\beta-S_{k}\right)}+(x-1)
$$

where $c_{k}=\prod_{j=0}^{k}\left(s_{j}+1\right)$ and $S_{k}=\sum_{j=0}^{k} x^{j} / c_{j}$.

Such a sequence of integers exists since

$$
\begin{aligned}
& c_{k}\left(\beta-S_{k}\right)=c_{k-1}\left(s_{k}+1\right)\left(\beta-S_{k-1}\right)-x^{k} \\
& \quad \leqq c_{k-1}\left(\frac{x^{k}}{c_{k-1}\left(\beta-S_{k-1}\right)}+x\right)\left(\beta-S_{k-1}\right)-x^{k}=x c_{k-1}\left(\beta-S_{k-1}\right)
\end{aligned}
$$

and hence

$$
s_{k} \leqq \frac{x^{k}}{c_{k-1}\left(\beta-S_{k-1}\right)}+(x-1) \leqq \frac{x^{k+1}}{c_{k}\left(\beta-S_{k}\right)}+(x-1) .
$$

The resulting series, $\sum_{i=0}^{\infty} x^{i} / c_{i}$ where $c_{i}=\prod_{j=0}^{i}\left(s_{j}+1\right)$, is a g.g.s. since $s_{k+1} \geqq s_{k}$. Also since $\beta \leqq 1$, 


$$
c_{1}=\left(s_{1}+1\right) c_{0}>\frac{c_{0} x}{c_{0} \beta-1}=\frac{c_{0} x}{\left(\left[\frac{1}{\beta}\right]+1\right) \beta-1} \geqq x c_{0} .
$$

Thus the series satisfies the hypotheses of the corollary to Theorem 2 . Now from the manner in which the sequence $\left\{s_{k}\right\}$ has been obtained, we have

$$
\frac{x^{k+1}}{c_{k}\left(\beta-S_{k}\right)}-1<s_{k+1} \leqq \frac{x^{k+1}}{c_{k}\left(\beta-S_{k}\right)}+(x-1)
$$

and thus

$$
\begin{aligned}
S_{k+1} & =S_{k}+\frac{x^{k+1}}{c_{k}\left(s_{k+1}+1\right)}<\beta \leqq S_{k}+\frac{x^{k+1}}{c_{k}\left(s_{k+1}+1-x\right)} \\
& =S_{k}+\frac{x^{k+1}}{c_{k+1}-x c_{k}} .
\end{aligned}
$$

Therefore, by (i) of the corollary, $\beta=\sum_{i=0}^{\infty} x^{i} / c_{i}$.

If $x \neq 1$, the sequence $\left\{s_{k}\right\}$ obtained by the above process is not unique. For example, if $\beta=1$ and $x=2$, we have $s_{0}=1$,

$$
\begin{aligned}
\max & \left\{\frac{x}{c_{0} \beta-1}-1, s_{0}-1\right\} \\
& =\max \{1,0\}=1 \text { and } \frac{x}{c_{0}-1}+x-1=3 .
\end{aligned}
$$

Thus there are two possible values for $s_{1}$. To obtain uniqueness, we must further restrict the $s_{k}$. One restriction that leads to a unique representation is to require that $s_{k} \geqq x s_{k-1}$. We now turn our attention to series which satisfy this condition.

THEOREM 3. Let $s>0, x \geqq 1$. For $k \geqq 0$, let $s_{k}=x^{k} s, c_{k}=$ $\prod_{i=0}^{k}\left(s_{i}+1\right)$. Then $\sum_{i=0}^{\infty} x^{i} / c_{i}=1 / s$; that $i s$

$$
\frac{1}{s}=\frac{1}{s+1}+\frac{x^{2}}{(s+1)(x s+1)}+\frac{x^{2}}{(s+1)(x s+1)\left(x^{2} s+1\right)}+\cdots .
$$

Proof. Let $S_{k}=\sum_{i=0}^{k} x_{i} / c_{i}$. We shall show by induction that $S_{k}+1 / c_{k} s=1 / s$ for all $k \geqq 0$. For $k=0$, we have

$$
s_{0}+\frac{1}{c_{0} s}=\frac{1}{c_{0}}\left(1+\frac{1}{s}\right)=\frac{1}{s+1}\left(\frac{s+1}{s}\right)=\frac{1}{s} .
$$

If $S_{k}+1 / c_{k} s=1 / s$, then 


$$
\begin{aligned}
S_{k+1} & +\frac{1}{c_{k+1} s}=S_{k}+\frac{x^{k+1}}{c_{k+1}}+\frac{1}{c_{k+1} s} \\
& =\frac{1}{s}-\frac{1}{c_{k} s}+\frac{1}{c_{k}}\left(\frac{s x^{k+1}+1}{s\left(s x^{k+1}+1\right)}\right)=\frac{1}{s} .
\end{aligned}
$$

It also follows by induction that $c_{k}>(s+1)^{k}$ and hence, since $s+1>1$, $\lim _{k \rightarrow \infty} 1 / c_{k} s=0$. Thus $\lim _{k \rightarrow \infty} S_{k}=\lim _{k \rightarrow \infty}\left(1 / s+1 / c_{k} s\right)=1 / s$.

Theorem 4. Let $x \geqq 1$. Let $\left\{s_{0}, s_{1}, s_{2}, \cdots\right\}$ be a sequence of positive integers such that $s_{k} \geqq x s_{k-1}$ for all $k \geqq 0$ and let $c_{k}=\prod_{i=0}^{k}\left(s_{i}+1\right)$. Then $\sum_{i=0}^{\infty} x^{i} / c_{i}$ is a convergent g.g.s. Furthermore if $\alpha=\sum_{i=0}^{\infty} x^{i} / c_{i}$ and $S_{k}=\sum_{i=0}^{k} x_{i} / c_{i}$ then

(i) the sequence of half-open intervals $\left\{\left(S_{k}, S_{k}+x^{k+1} /\left(c_{k+1}-c_{k}\right)\right]\right\}$ is a sequence of nested intervals whose intersection is $\alpha$,

(ii) $s_{k+1}=\left[x^{k+1} / c_{k}\left(\alpha-S_{k}\right)\right]$ for all $k \geqq 0, s_{0}=[1 / \alpha]$,

(iii) if $x$ is rational, then $\alpha$ is rational if and only if $s k=x s_{k-1}$ for all $k$ sufficiently large.

Proof. Since $c_{i} / c_{i-1}=s_{i}+1 \leqq s_{i+1}+1=c_{i+1} / c_{i}$, it follows that

$$
\left(\frac{c_{i}}{x^{i}}\right)^{2} \leqq\left(\frac{c_{i-1}}{x^{i-1}}\right)\left(\frac{c_{i+1}}{x^{i+1}}\right)
$$

and hence $\sum_{i=0}^{\infty} x^{i} / c_{i}$ is a g.g.s. The series converges by Theorem 1 since $c_{0}<c_{1} / x$.

To establish (i), we first observe that $s_{k+j+1} \geqq x^{j} s_{k+1}$ for all $j \geqq 0$. Thus, using Theorem 3 , we have

$$
\begin{aligned}
S_{k}< & \alpha=S_{k}+\sum_{i=0}^{\infty} \frac{x^{k+j+1}}{c_{k+j+1}} \\
= & S_{k}+\frac{x^{k+1}}{c_{k}}\left(\frac{1}{s_{k+1}+1}+\frac{x}{\left(s_{k+1}+1\right)\left(s_{k+2}+1\right)}\right. \\
& \left.+\frac{x^{2}}{\left(s_{k+1}+1\right)\left(s_{k+2}+1\right)\left(s_{k+3}+1\right)}+\cdots\right) \\
\leqq & S_{k}+\frac{x^{k+1}}{c_{k}}\left(\frac{1}{s_{k+1}+1}+\frac{x}{\left(s_{k+1}+1\right)\left(x s_{k+1}+1\right)}\right. \\
& \left.+\frac{x^{2}}{\left(s_{k+1}+1\right)\left(x s_{k+1}+1\right)\left(x^{2} s_{k+1}+1\right)}+\cdots\right) \\
= & S_{k}+\frac{x^{k+1}}{c_{k}} \cdot \frac{1}{s_{k+1}}=S_{k}+\frac{x^{k+1}}{c_{k+1}-c_{k}} \cdot
\end{aligned}
$$

Furthermore, since $s_{k+2}-x s_{k+1} \geqq 0$, we have 


$$
\begin{gathered}
\frac{x^{k+1}}{c_{k} s_{k+1}}-\frac{x^{k+2}}{c_{k+1} s_{k+2}}=\frac{x^{k+1}}{c_{k+1}}\left(\frac{s^{k+1}+1}{s_{k+1}}-\frac{x}{s_{k+2}}\right) \\
=\frac{x^{k+1}}{c_{k+1}}\left(1+\frac{1}{s_{k+1}}-\frac{x}{s_{k+2}}\right) \geqq \frac{x^{k+1}}{c_{k+1}} .
\end{gathered}
$$

Thus

$$
S_{k+1}+\frac{x^{k+2}}{c_{k+1} s_{k+2}}=S_{k}+\frac{x^{k+1}}{c_{k+1}}+\frac{x^{k+2}}{c_{k+1} s_{k+2}} \leqq S_{k}+\frac{x^{k+1}}{c_{k} s_{k+1}}
$$

and the sequence of intervals in (i) is nested. Since

$$
S_{k}+\frac{x^{k+1}}{c_{k+1}-c_{k}} \leqq S_{k}+\frac{x^{k+1}}{c_{k+1}-x c_{k}}
$$

by part (i) of the corollary to Theorem 2 , the intersection of the intervals is $\alpha$.

To establish (ii), we have from (i) that

$$
S_{k}+\frac{x^{k+1}}{c_{k}\left(s_{k+1}+1\right)}=S_{k+1}<\alpha \leqq S_{k}+\frac{x^{k+1}}{c_{k} s_{k+1}} .
$$

Solving these inequalities for $s_{k+1}$, we have

$$
\frac{x^{k+1}}{c_{k}\left(\alpha-S_{k}\right)}-1<s_{k+1} \leqq \frac{x^{k+1}}{c_{k}\left(\alpha-S_{k}\right)} .
$$

Also, since $s_{k} \geqq x^{k} s_{0}$, using Theorem 3 , we have

$$
\begin{gathered}
\frac{1}{s_{0}+1}=S_{0}<\alpha \leqq \frac{1}{s_{0}+1}+\frac{1}{\left(s_{0}+1\right)\left(x s_{0}+1\right)} \\
+\frac{x^{2}}{\left(s_{0}+1\right)\left(x s_{0}+1\right)\left(x^{2} s_{0}+1\right)}+\cdots=\frac{1}{s_{0}}
\end{gathered}
$$

and hence $s_{0} !=[1 / \alpha]$.

We turn now to the proof of (iii). Suppose $s_{k}=x s_{k-1}$ for all $k>k_{0}$. Then $s_{k_{0}+j}=x^{j} s_{k_{0}}$ for all $j \geqq 0$. Thus, again using Theorem 3 , we have

$$
\begin{aligned}
\alpha= & S_{k_{0}-1}+\frac{x^{k_{0}}}{c_{k_{0}-1}}\left(\frac{1}{s_{k_{0}+1}}\right. \\
& \left.+\frac{x}{\left(s_{k_{0}+1}\right)\left(x s_{k_{0}}+1\right)}+\frac{x^{2}}{\left(s_{k_{0}+1}\right)\left(x s_{k_{0}+1}\right)\left(x^{2} s_{k_{0}+1}\right)}+\cdots\right) \\
= & S_{k_{0}-1}+\frac{x^{k_{0}}}{c_{k_{0}-1}} \cdot \frac{1}{s_{k_{0}}}
\end{aligned}
$$


which is rational if $x$ is rational.

Conversely, suppose $\alpha$ is rational. From (2) we have

$$
\frac{x^{k+1}}{s_{k+1}+1}<C_{k}\left(\alpha-S_{k}\right) \leqq \frac{x^{k+1}}{s_{k+1}} .
$$

Thus

$$
\begin{aligned}
0< & c_{k+1}\left(\alpha-S_{k+1}\right)=c_{k+1}\left(\alpha-S_{k}-\frac{x^{k+1}}{c_{k+1}}\right) \\
& =c_{k}\left(s_{k+1}+1\right)\left(\alpha-S_{k}\right)-x^{k+1} \\
& \leqq c_{k}\left(\frac{x^{k+1}}{c_{k}\left(\alpha-S_{k}\right)}+1\right)\left(\alpha-S_{k}\right)-x^{k+1}=c_{k}\left(\alpha-S_{k}\right)
\end{aligned}
$$

Hence, if $\alpha=p / q$, for all $k$ we have

$$
0<c_{k+1}\left(p-S_{k+1} q\right) \leqq c_{i k}\left(p-S_{k} q\right) \text {. }
$$

Therefore, noting that $c_{k} S_{k}$ is an integer, $\left\{c_{k}\left(p-S_{k} q\right)\right\}$ is a nonincreasing sequence of positive integers and thus for $k$ sufficiently large, say $k>k_{0}$, the terms of the sequence become constant. Hence, for $k>k_{0}$, $c_{k+1}\left(\alpha-S_{k+1}\right)=c_{k}\left(\alpha-S_{k}\right)$ and thus equality must hold in (3). Therefore $s_{k+1}=x^{k+1} / c_{k}\left(\alpha-S_{k}\right)$ for $k>k_{0}$ and, for $k$ sufficiently large,

$$
s_{k+1}=\frac{x^{k+1}}{c_{k}\left(\alpha-S_{k}\right)}=x \cdot \frac{x^{k}}{c_{k-1}\left(\alpha-S_{k-1}\right)}=x s_{k} .
$$

Theorem 5. Let $0<\beta \leqq 1$ and let $x$ be a positive integer. Then there exists a unique sequence of positive integers $\left\{s_{0}, s_{1}, s_{2} \cdots\right\}$ such that $s_{k} \geqq x s_{k-1}$ for $k \geqq 1$ and $\beta=\sum_{i=0}^{\infty} x^{i} / c_{i}$ where $c_{i}=\prod_{i=0}^{k}\left(s_{i}+1\right)$.

Proof. Define

$$
s_{0}=\left[\frac{1}{\beta}\right], \quad c_{0}=s_{0}+1, \quad S_{0}=\frac{1}{c_{0}}
$$

and, for $k>0$,

$$
s_{k+1}=\left[\frac{x^{k+1}}{c_{k}\left(\beta-S_{k}\right)}\right], \quad c_{k+1}=\left(s_{k+1}+1\right) c_{k}, \quad S_{k+1}=S_{k}+\frac{x^{k+1}}{c_{k+1}} .
$$

Then, in the same manner as inequality (3) was obtained, we have

$$
c_{k+1}\left(\beta-S_{k+1}\right) \leqq c_{k}\left(\beta-S_{k}\right) \text {. }
$$

Thus 


$$
\begin{aligned}
s_{k+1} & >\frac{x^{k+1}}{c_{k}\left(\beta-S_{k}\right)}-1 \geqq \frac{x^{k+1}}{c_{k-1}\left(\beta-S_{k-1}\right)}-1 \\
& =x\left(\frac{x^{k}}{c_{k-1}\left(\beta-S_{k-1}\right)}\right)-1 \geqq x s_{k}-1 .
\end{aligned}
$$

Since $s_{k+1}$ and $x s_{k}-1$ are integers, it follows that $s_{k+1} \geqq x s_{k}$. Also from the definition of $s_{k+1}$,

$$
\frac{x^{k+1}}{c_{k}\left(\beta-S_{k}\right)}-1<s_{k+1} \leqq \frac{x^{k+1}}{c_{k}\left(\beta-S_{k}\right)} .
$$

Therefore

$$
S_{k}<S_{k+1}=S_{k}+\frac{x^{k+1}}{c_{k+1}}<\beta \leqq S_{k}+\frac{x^{k+1}}{c_{k}\left(\beta-S_{k}\right)}
$$

Thus from Theorem 4 (i), $\beta=\sum_{i=0}^{\infty} x^{i} / c_{i}$. The uniqueness of the sequence $\left\{s_{k}\right\}$ follows from Theorem 4 (ii).

Received March 20, 1968.

UNIVERSITY OF OREGON AND

PACIFIC Lutheran UNIVERSITY 



\section{PACIFIC JOURNAL OF MATHEMATICS}

\section{EDITORS}

\author{
H. ROYDEN \\ Stanford University \\ Stanford, California \\ R. R Phelps \\ University of Washington \\ Seattle, Washington 98105
}

\author{
J. Dugundui \\ Department of Mathematics \\ University of Southern California \\ Los Angeles, California 90007
}

RICHARD ARENS

University of California

Los Angeles, California 90024

\section{ASSOCIATE EDITORS}
E. F. BeCKENBACH
B. H. NeUmanN
F. WolF
K. YosidA

\section{SUPPORTING INSTITUTIONS}

\author{
UNIVERSITY OF BRITISH COLUMBIA \\ CALIFORNIA INSTITUTE OF TECHNOLOGY \\ UNIVERSITY OF CALIFORNIA \\ MONTANA STATE UNIVERSITY \\ UNIVERSITY OF NEVADA \\ NEW MEXICO STATE UNIVERSITY \\ OREGON STATE UNIVERSITY \\ UNIVERSITY OF OREGON \\ OSAKA UNIVERSITY \\ UNIVERSITY OF SOUTHERN CALIFORNIA
}

\author{
STANFORD UNIVERSITY \\ UNIVERSITY OF TOKYO \\ UNIVERSITY OF UTAH \\ WASHINGTON STATE UNIVERSITY \\ UNIVERSITY OF WASHINGTON

$* * * * *$
AMERICAN MATHEMATICAL SOCIETY
CHEVRON RESEARCH CORPORATION
TRW SYSTEMS
NAVAL WEAPONS CENTER

The Supporting Institutions listed above contribute to the cost of publication of this Journal, but they are not owners or publishers and have no responsibility for its content or policies.

Mathematical papers intended for publication in the Pacific Journal of Mathematics should be in typed form or offset-reproduced, double spaced with large margins. Underline Greek letters in red, German in green, and script in blue. The first paragraph or two must be capable of being used separately as a synopsis of the entire paper. It should not contain references to the bibliography. Manuscripts, in duplicate if possible, may be sent to any one of the four editors. Please classify according to the scheme of Math. Rev. 36, 1539-1546. All other communications to the editors should be addressed to the managing editor, Richard Arens, University of California, Los Angeles, California, 90024.

50 reprints are provided free for each article; additional copies may be obtained at cost in multiples of 50 .

The Pacific Journal of Mathematics is published monthly. Effective with Volume 16 the price per volume (3 numbers) is $\$ 8.00$; single issues, $\$ 3.00$. Special price for current issues to individual faculty members of supporting institutions and to individual members of the American Mathematical Society: $\$ 4.00$ per volume; single issues $\$ 1.50$. Back numbers are available.

Subscriptions, orders for back numbers, and changes of address should be sent to Pacific Journal of Mathematics, 103 Highland Boulevard, Berkeley, California, 94708.

PUBLISHED BY PACIFIC JOURNAL OF MATHEMATICS, A NON-PROFIT CORPORATION

Printed at Kokusai Bunken Insatsusha (International Academic Printing Co., Ltd.), 7-17. Fujimi 2-chome, Chiyoda-ku, Tokyo, Japan. 


\section{Pacific Journal of Mathematics}

Vol. 28, No. 3

May, 1969

Jon F. Carlson, Automorphisms of groups of similitudes over $F_{3} \ldots \ldots \ldots$

W. Wistar (William) Comfort, Neil Hindman and Stelios A. Negrepontis,

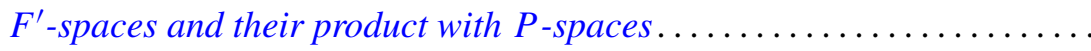

Archie Gail Gibson, Triples of operator-valued functions related to the unit

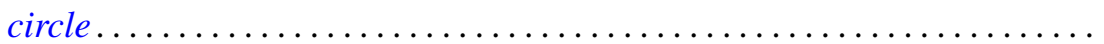

David Saul Gillman, Free curves in $E^{3}$

E. A. Heard and James Howard Wells, An interpolation problem for

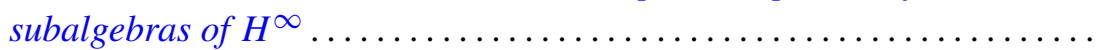

Albert Emerson Hurd, A uniqueness theorem for weak solutions of symmetric

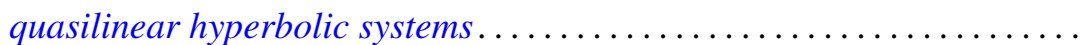

E. W. Johnson and J. P. Lediaev, Representable distributive Noether

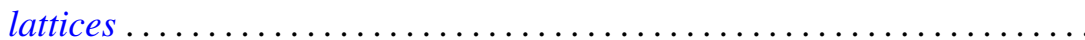

David G. Kendall, Incidence matrices, interval graphs and seriation in

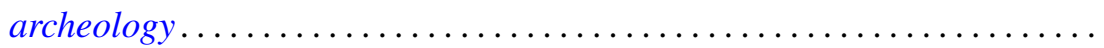
565

Robert Leroy Kruse, On the join of subnormal elements in a lattice ....... 571

D. B. Lahiri, Some restricted partition functions; Congruences modulo 3 .... 575

Norman D. Lane and Kamla Devi Singh, Strong cyclic, parabolic and conical differentiability........................................

William Franklin Lucas, Games with unique solutions that are

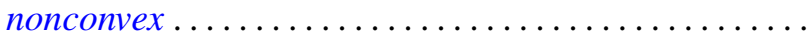

Eugene A. Maier, Representation of real numbers by generalized geometric series.

Daniel Paul Maki, A note on recursively defined orthogonal polynomials ...

Mark Mandelker, $F^{\prime}$-spaces and z-embedded subspaces ...

James R. McLaughlin and Justin Jesse Price, Comparison of Haar series with gaps with trigonometric series

Ernest A. Michael and A. H. Stone, Quotients of the space of irrationals ....

William H. Mills and Neal Zierler, On a conjecture of Golomb ...

J. N. Pandey, An extension of Haimo's form of Hankel convolutions ...

Terence John Reed, On the boundary correspondence of quasiconformal mappings of domains bounded by quasicircles...

Haskell Paul Rosenthal, A characterization of the linear sets satisfying Herz's criterion.

George Thomas Sallee, The maximal set of constant width in a lattice...

I. H. Sheth, On normaloid operators

James D. Stasheff, Torsion in BBSO ...

Billy Joe Thorne, A - P congruences on Baer semigroups.

Robert Breckenridge Warfield, Jr., Purity and algebraic compactness for

modules... 